\title{
Bipolar disorder increases the risk of poor sleep quality among senior high school students
}

\author{
Surilena Hasan* and Christopher Yovan Junardi**
}

\begin{abstract}
BACKGROUND

Patients with bipolar disorder commonly experience sleeping problems. On the other hand, sleep disturbances have been suggested as one of the symptoms that indicate the development of bipolar disorder. Considering the detrimental effect of bipolar disorder, especially in young people, this study aimed to determine the relationship between sleep quality and risk of bipolar disorder in senior high school students.
\end{abstract}

\section{METHODS}

A cross-sectional study was conducted involving 725 senior high school students. The instruments used were a demographic questionnaire, Young Mania Rating Scale (YMRS), MINI International Neuropsychiatric Interview (MINI ICD-10), Hypomania/Mania Symptom Checklist (HCL-32), and Pittsburgh Sleep Quality Index (PSQI). Univariate and bivariate (simple logistic regression) analyses were performed to evaluate the relation between sleep quality and the risk of bipolar disorder.

\section{RESULTS}

Around $28 \%$ of subjects were at risk of bipolar disorder, of which $96.6 \%$ were prone to type I, and the rest were type II. Most of the participants with bipolar disorder $(64 \%)$ had poor sleep quality. The percentage of participants with type I bipolar disorder that had poor sleep quality was higher than that of type II (65.3\% and $28.6 \%$, respectively). There was a significant relationship between bipolar disorder and sleep quality $(\mathrm{OR}=$ $2.2 ; 95 \% \mathrm{CI}=1.581-3.087 ; \mathrm{p}=0.000)$.

\section{CONCLUSIONS}

Our study demonstrated that in senior high school students, bipolar disorder increased the risk of poor sleep quality. Assessment of sleep disturbances routinely in psychiatric interviews may improve sleep quality.

Keywords: Bipolar disorder, sleep quality, senior high school student
*Department of Psychiatry and Behavioural Sciences, School of Medicine and Health Sciences, Atma Jaya Catholic University of Indonesia, Jakarta

**Study Program of Medicine School of Medicine and Health Sciences, Atma Jaya Catholic University of Indonesia, Jakarta

\section{Correspondence:}

Surilena

School of Medicine and Health

Sciences,

Atma Jaya Catholic University of Indonesia

Jl. Pluit Raya No. 2,

Jakarta Utara 14440

Mobile: +6281289769996

Email: surilena@atmajaya.ac.id ORCID ID : 0000-0001-6164-1117

Date of first submission, December 30, 2019

Date of final revised submission,

August 17, 2020

Date of acceptance, August 19, 2020

This open access article is distributed under a Creative Commons AttributionNon Commercial-Share Alike 4.0 International License

Cite this article as: Hasan S, Junardi $\mathrm{CV}$. Bipolar disorder increases the risk of poor sleep quality among senior high school students Univ Med 2020;39:12834. doi: 10.18051/UnivMed.2020. v39.128-134 


\section{INTRODUCTION}

Bipolar disorder is considered a chronic and detrimental condition. Bipolar disorder is common in clinical psychiatric practice, and several studies have estimated its prevalence to range from 0.5 to $5 \%$ in community-based samples. ${ }^{(1)}$ In South East Asia, the proportion of type I bipolar disorder is $0.6 \%$ and that of type II is $0.4 \%$. $^{(2)}$ However, establishing the diagnosis in both children and adolescents is still challenging. In fact, the prevalence of paediatric bipolar has been a subject of debate in published literature. A meta-analytical study stated that the prevalence rate of bipolar disorder in children and adolescents across 12 studies was $1.8 \%$. $^{(3)}$ The International Classification of Diseases (ICD 10) defines bipolar disorder as a medical condition characterised by two or more episodes of significant disturbance in mood and activity level, which consists of some occasions of an elevated mood, increased energy and activity (hypomania or mania), and others of a lowered mood and decreased energy and activity (depression). ${ }^{(4)}$ There are two types of bipolar disorder, namely type I bipolar disorder with manic and type II bipolar disorder with hypomanic episodes as the essential features. While a major depressive episode is essential for the diagnosis of type II bipolar disorder, it is not required for type I bipolar disorder. ${ }^{(5)}$

Clinical studies on patients with bipolar disorder have suggested that sleeping problems and sleep disturbances are symptoms indicating the development of bipolar disorder. ${ }^{(6,7)}$ A recent study by Ritter et al. ${ }^{(8)}$ indicated that poor sleep quality significantly increases the risk of bipolar disorder among adolescents and young adults. The study of Levenson et al. ${ }^{(9)}$ suggested that those who are at risk, such as offspring of bipolar disorder patients, are more likely to develop the same diagnosis when they are poor sleepers. While a wide range of longitudinal studies have established insomnia to be a risk factor for the subsequent onset of major depression no such evidence is available with regard to BD so far. ${ }^{(10)}$
The need to gain a deeper understanding on bipolar disorder, particularly in children and adolescents, is commonly acknowledged. ${ }^{(11)}$ It is considered important to add studies from nonWestern countries since most published literature come from the Northern hemisphere. (2) Since mental health among children and adolescents will impose a serious health burden on developing countries like Indonesia, research from our country to gain more comprehensive insight concerning paediatric bipolar disorder would be very strategic and valuable. As a developing nation Indonesia needs quality human resources. Research that contributes to improving the continuum of care in mental health disorders for the young generation should have urgency and priority. ${ }^{(12)}$ Therefore, the present study aimed at providing a new insight on bipolar disorder and its relationship with sleep quality among senior high school students.

\section{METHODS}

\section{Research design}

This was a cross-sectional study involving children and adolescents in the age range of 14 to 20 years, aimed at evaluating sleep quality among adolescents at risk of bipolar disorder. This study was performed from November to December 2017 at four high schools in North Penjaringan district, North Jakarta.

\section{Research subjects}

The participants of this study were students from the selected senior high schools. A total of 725 participants responded to the questionnaire and were included into the study. The inclusion criterion was all year 10, 11, and 12 students. The exclusion criteria were students who were absent, unwilling to be a participant, and refused to sign informed consent.

\section{Measurements}

Several instruments were used to assess the risk of bipolar disorder, namely Young Mania Rating Scale (YMRS), Mini International 
Neuropsychiatric Interview (MINI ICD-10), and Hypomania Symptom Checklist (HCL-32).

The YMRS is an 11-item questionnaire to assess symptoms of mania. It has proven to be reliable \{interrater reliability $($ IRR $)=0.93, \mathrm{p}<0.001)$ and valid (concurrent validity with global rating, $\mathrm{r}=0.86$, $\mathrm{p}<0.001)$ to measure the severity of mania symptoms. Each item of the YMRS assesses a different component of mania, namely elevated mood, increased motor activity or energy, sexual interest, sleep, irritability, speech (rate and amount), language (thought disorder), content, disruptive or aggressive behaviour, appearance, and insight. The responses to these items are on a five-point Likert scale. The total score from all 11 items is used to determine the condition of mania. Score 12 or above means that the person has mania. ${ }^{(13)}$

The MINI is a short-structured diagnostic interview for mental disorders listed in ICD-10, and has a good reliability for the assessment of major depressive disorder (test/retest Kappa $=$ 0.76). The questions in the MINI for depression are grouped into two parts. The first part consists of questions asking about symptoms of major depressive disorder, namely depressed mood, lack or loss of interest, and lack of energy, experienced by a person in the last two weeks. If a respondent answers 'yes' to two or more items, than they should continue to the second part, which is a continuation of the first part. Questions in the second part ask about other symptoms, such as loss of weight, sleeping pattern, slow speech and movement, self-confidence, guilt feelings, lack of concentration, and self-harm or suicide. Each 'yes' answer receives one point, such that a total score of four or above means depression. In other words, a respondent who answers 'yes' to four or more questions is considered as having depression. ${ }^{(14)}$

The HCL-32 was developed to help clinicians in assessing the symptoms of hypomania and establish the diagnosis of type II bipolar disorder. The sensitivity for type II bipolar disorder of the HCL-32 was $80 \%$ in comparison to unipolar depression or other non-bipolar disorders, while it was $65.3 \%$ and $57.3 \%$ compared to the unipolar depression and other diagnoses, respectively. It consists of 32 items, which should be responded to with 'yes' (score=1) or 'no' (score=2). The total score of 16 or above reflects hypomania. ${ }^{(15)}$

The measurements were performed in sequences. First, the symptoms of mania were determined using the YMRS. The participants who did not have mania (YMRS total score $<12$ ) were further evaluated using the MINI ICD-10 to determine the depression symptoms. Finally, those who had depression symptoms (MINI ICD10 total score $\geq 4$ ) were evaluated using the HCL2. The risk of type I bipolar disorder was concluded for the participants who had a YMRS score of $\geq 12$ (mania) and a MINI ICD-10 score of $\geq 4$ (depression). The risk of type II bipolar disorder was concluded for those who had a MINI ICD-10 total score of $\geq 4$ (depression) and a HCL-32 score of e"16 (hypomania). ${ }^{(13-15)}$

The Pittsburgh Sleep Quality Index (PSQI) is used to measure sleep quality and the presence of sleep disturbances at 30-day intervals. The psychometric properties of the PSQI are good in comparing good and poor sleepers, with sensitivity of $89.6 \%$ and specificity of $86.5 \%$ (kappa $=0.75$, $\mathrm{p} \leq 001)$. It can be used to assess sleeping problems among clinical and non-clinical populations. This questionnaire consists of seven components, namely the quality of sleep, the length of time required to fall asleep, the duration of sleep, the efficiency of sleep, the presence or absence of sleep disturbances, the use of sleeping pills, and work functions at productive hours. The total score of all seven components determines the sleep quality. A total score of five or above means poor sleep quality, while below five means good sleep quality. ${ }^{(16)}$

\section{Statistical analysis}

The sample group was divided into two groups according to PSQI score. In order to find the predictors of subjects with clinically significant sleep disturbance, simple logistic regression analysis was used. All $\mathrm{p}$ values were two-tailed, and statistical significance was set as $p<0.05$. 
Table 1. Characteristics, bipolar disorder and type of bipolar disorder

\begin{tabular}{ccc}
\hline Characteristic & n (\%) & Mean \pm SD \\
\hline Age (years) Range & $14-20$ & $16.5 \pm 0.988$ \\
14 & $2(0.3)$ & \\
15 & $128(17.7)$ & \\
16 & $218(30.1)$ & \\
17 & $281(38.8)$ & \\
18 & $84(11.6)$ & \\
19 & $9(1.2)$ & \\
20 & $3(0.4)$ & \\
Gender & & \\
Male & $321(44.3)$ & \\
Female & $404(55.7)$ & \\
High School Grade & & \\
$10^{\text {th }}$ & $217(29.9)$ & \\
$11^{\text {th }}$ & $239(33,0)$ & \\
13 & $269(37.1)$ & \\
Sleep Quality & & \\
Poor & $363(50.1)$ & \\
Good & $362(49.9)$ & \\
Bipolar Disorder & & \\
No Risk & $522(72)$ \\
Risk: & $203(28)$ \\
Type I & $196(96.6)$ \\
Type II & $7(3.4)$ \\
\hline
\end{tabular}

\section{Ethical clearance}

The Ethical Research Committee of the School of Medicine and Health Sciences, Atma Jaya Catholic University of Indonesia, had approved this study on November $20^{\text {th }}, 2017$ under no. 10/11/KEP-FKUAJ/2017.

\section{RESULTS}

Most participants were female $(55.7 \%$, $)$, and in year $12(37.1 \%)$. The mean age of the participants was 16.5 years. Slightly more than half of them $(50.1 \%)$ had poor sleep quality. Almost a third (28\%) of the participants were at risk of bipolar disorder, of which $96.6 \%$ were prone to type I bipolar disorder, and the rest were type II bipolar disorder (Table 1). More than half of those who were at risk of type I bipolar disorder were female $(55.1 \%)$, while $57.1 \%$ of those at risk of type II bipolar disorder were male (data not presented).

Most of the participants with bipolar disorder (64\%) had poor sleep quality. There was a significant relationship between bipolar disorder and sleep quality $(\mathrm{OR}=2.2 ; 95 \% \mathrm{CI}=1.581-3.087$; $\mathrm{p}=0.000$ ). Those who were at risk of bipolar disorder had 2.2 times poorer sleep quality compared to students without bipolar disorder.

This study showed that $65.3 \%$ participants with type I bipolar disorder had poor sleep quality, while the percentage of type II bipolar disorder with poor sleep quality was only $28.6 \%$. There was no significant correlation between the type of bipolar disorder and sleep quality. ( $\mathrm{OR}=4.7$; 95\% CI=0.889-24.898; $\mathrm{p}=0.111$ ) (Table 2).

\section{DISCUSSION}

This study found that the majority of students who were at risk of bipolar disorder were at risk of type I bipolar disorder, and were more likely to have sleeping problems compared to those who were not at risk. Second, those who were at risk of type I bipolar disorder were more likely to have poor sleep quality compared to those who were at risk of type II bipolar disorder. The prevalence of students who were at risk of bipolar disorder (28\%) was much higher than the global prevalence reported in previous studies $(0 \%$ $7 \%)^{(2,4)}$ The present study used YMRS, MINI ICD-10 and HCl-32 instruments without structured psychiatric interviews, in contrast to the previous studies that used structured psychiatric interviews. The results of the present study indicate that adolescents had a high risk of bipolar disorder (28\%). This shows that early onset of bipolar disorder is more common in

Table 2. Logistic regression analysis to predict bipolar disorder and type for poor sleep quality

\begin{tabular}{lccc}
\hline & \multirow{2}{*}{ OR } & \multicolumn{2}{c}{ 95\% C.I. for OR } \\
\cline { 3 - 4 } & & Low & High \\
\hline Bipolar disorder & 2.209 & 1.581 & 3.087 \\
Bipolar disorder type & 4.706 & 0.889 & 24.898 \\
\hline
\end{tabular}

OR : Odds Ratio 
adolescents and therefore it is necessary to do early detection of bipolar disorder in adolescents, especially in educational institutions so that interventions can be carried out as early as possible to prevent the effects that may arise.

The findings of the present study were similar to those of a previous study, which showed that sleeping problems commonly occur in adolescents at risk of bipolar disorder. ${ }^{(17)}$ One study suggested that sleep onset latency occurs more often in the offspring of patients with bipolar disorder compared to the control group. ${ }^{(18)}$ Similar findings were found in another study that showed poorer sleep quality in adolescents who had one parent with bipolar disorder than in the control group. ${ }^{(19)}$ Importantly, they also found that adolescents at risk of bipolar disorder who had sleeping problems were more likely to develop bipolar disorder than their counterparts, ${ }^{(18)}$ and sleep disturbances were recognised as one of prodromal symptoms of paediatric bipolar disorder. ${ }^{(17)}$ Considering that most of our participants who were at risk also experienced sleeping problems, it is essential to regularly evaluate their condition and provide relevant intervention to prevent the development of bipolar disorder.

There are no published studies reporting the difference in sleep quality between type I and type II bipolar disorder among adolescents. Indeed, Steinan et al. ${ }^{(20)}$ reported that hypersomnia was related to type I bipolar disorder, and this relation was more likely to occur in the younger age group. However, they performed their study among adult participants (mean age $=38$ ). One previous study evaluated sleeping patterns between adolescents with type I bipolar disorder and bipolar disorder not otherwise specified (bipolar NOS), and found no significant difference, although the percentages of insomnia and any sleep disorder were higher in the latter. ${ }^{(21)}$ In type I bipolar disorder problems in sleeping are associated with more severe conditions. For example, longer latency period and more frequent awakening during the night were associated with depressed mood, while the variability in sleeping duration was related to impulsive behaviour. ${ }^{(22)}$ Hence, further studies should evaluate whether sleep quality in type II bipolar disorder can influence the progression of the disorder. In our research, the risk in adolescents for type I bipolar disorder and type II was not significantly associated with poor sleep quality. This may have been due to the fact that the number of adolescents who were at risk for type I bipolar disorder was much greater than those at risk for type II bipolar disorder.

There are several limitations of this study that need to be pointed out. First, we performed the study in only four high schools of one district in Jakarta. Therefore, the generalizability of the findings could be questionable. However, considering that this is the first study that explored the association between sleep quality and risk of bipolar disorder among high school students, the findings provide recommendation for future studies to evaluate other aspects of bipolar disorder, particularly in adolescents. Second, we did not assess other factors that might contribute to the risk of bipolar disorder and sleep quality, such as history of mental disorder in the family, parenting functions, or individual coping skills. Third, our study measured sleep quality using a self-report instrument, which may produce a measurement bias. More research using objective measurement of sleep should be pursued to support these data and to further investigate the causal relationship between sleep quality and bipolar disorders. Finally, in this study YMRS, MINI ICD-10 and HCl-32 instruments were used without structured psychiatric interviews, whereas the other studies used structured psychiatric interviews. Future studies should evaluate the aforementioned factors to provide more understanding about bipolar disorder in adolescents.

\section{CONCLUSION}

Our study confirmed that BD increased the risk of poor sleep quality in high school students. Importantly, a prevention program is highly 
recommended at school to improve students' mental health. Finally, detection and intervention programs for students at risk are required for early diagnosis and treatment.

\section{CONFLICT OF INTEREST}

Competing interests: No relevant disclosures

\section{ACKNOWLEDGEMENT}

The author thanks the headmasters and teachers of the four high schools in Penjaringan district, North Jakarta who had permitted this study and all high school students that were willing to participate and signed informed consent.

\section{AUTHOR'S CONTRIBUTIONS}

S contributed to write the draft of the and design the study. CYJ supervised and/or performed the data management and data entry. $\mathrm{S}$ and SCYJ contributed to analysis and interpretation of the data.. All authors have read and approved the final manuscript.

\section{REFERENCES}

1. Carlson GA, Dubicka B. Very early onset bipolar disorder - international differences in prevalence, practice or language? Child Adolesc Ment Health 2019;24:86-7. https://doi.org/10.1111/camh.12315.

2. Melo MCA, Garcia RF, Neto VBL, et al. Sleep and circadian alterations in people at risk for bipolar disorder: a systematic review. J Psychiatr Res 2016;83:211-9. https://doi.org/10.1016/ j.jpsychires.2016.09.005.

3. van Meter A, Moreira ALR, Youngstrom E. Updated meta-analysis of epidemiologic studies of pediatric bipolar disorder. J Clin Psychiatry 2019;80:18r12180. doi: 10.4088/JCP.18r12180.

4. World Health Organization. International Statistical Classification of Diseases and Related Health Problems 10th Revision. Geneva :World Health Organization; 2016.

5. Bobo WV. The diagnosis and management of bipolar I and II disorders: clinical practice update. Mayo Clinic Proceedings 2017;92:1532-51. https:/ /doi.org/10.1016/j.mayocp.2017.06.022.
6. Melo MCA, Abreu RLC, Neto VBL, de Bruin PFC, de Bruin VMS. Chronotype and circadian rhythm in bipolar disorder: a systematic review. Sleep Medicine Rev 2017;34:46-58. doi: 10.1016/ j.smrv.2016.06.007.

7. Skjelstad DV, Malt UF, Holte A. Symptoms and signs of the initial prodrome of bipolar disorder: a systematic review. J Affect Disord 2010;126:1. DOI: 10.1016/j.jad.2009.10.003

8. Ritter PS, Höfler M, Wittchen HU, et al. Disturbed sleep as risk factor for the subsequent onset of bipolar disorder - data from a 10-year prospectivelongitudinal study among adolescents and young adults. J Psychiatr Res 2015;68:76-82. doi: 10.1016/j.jpsychires.2015.06.005.

9. Levenson JC, Soehner A, Rooks B, et al. Longitudinal sleep phenotypes among offspring of bipolar parents and community controls. J Affect Disord 2017;215:30-6. https://doi.org/ 10.1016/j.jad.2017.03.011.

10. Baglionia C, Battaglieseb G, Feigea B, et al. Insomnia as a predictor of depression: a metaanalytic evaluation of longitudinal epidemiological studies. J Affect Disord 2011;135:10-9. https://doi.org/10.1016/ j.jad.2011.01.011.

11. Findling RL, Stepanova E, Youngstrom EA, Young AS. Progress in diagnosis and treatment of bipolar disorder among children and adolescents: an international perspective. Evidence Based Mental Health 2018;21:177. http:/ /dx.doi.org/10.1136/eb-2018-102912.

12. Maramis MM, Karimah A, Yulianti E, Bessing YF. Screening of bipolar disorders and characteristics of symptoms in various populations in Surabaya, Indonesia. Anima Indonesian Psychol J 2017;32:90-8. https://doi.org/10.24123/ aipj.v32i2.587.

13. Cazorla P, Zhao J, Mackle M, Szegedi A. Asenapine effects on individual Young Mania Rating Scale items in bipolar disorder patients with acute manic or mixed episodes: a pooled analysis. Neuropsychiatr Dis Treat 2013;9:40913. doi: 10.2147/NDT.S38390.

14. Øhre B, Saltnes H,von Tetzchner S, Falkum E. Psychometric properties of a sign language version of the Mini International Neuropsychiatric Interview (MINI). BMC Psychiatry 2014; 14: 148. doi: 10.1186/1471-244X-14-148.

15. Soares OT, Moreno DH, de Moura EC, Angst J, Moreno RA. Reliability and validity of a Brazilian version of the Hypomania Checklist (HCL-32) compared to the Mood Disorder Questionnaire (MDQ). Rev Bras Psiquiatr 2010;32:416-23. doi: 10.1590/s1516-44462010000400015. 
16. Buysse DJ, Reynolds III CF, Monk TH, Berman SR, Kupfer DJ. The Pittsburgh Sleep Quality Index: a new instrument for psychiatric practice and research. Psychiatry Res 1989;28:193-213. doi: 10.1016/0165-1781(89)90047-4.

17. Hernandez M, Marangoni C, Grant MC, Estrada J, Faedda GL. Parental reports of prodromal psychopathology in pediatric bipolar disorder. Curr Neuropharmacol 2017;15:380-5. doi: 10.2174/ 1570159X14666160801162046.

18. Sebela A, Novak T, Kemlink D, Goetz M. Sleep characteristics in child and adolescent offspring of parents with bipolar disorder: a case control study. BMC Psychiatr 2017;17:199. https:// doi.org/10.1186/s12888-017-1361-8.

19. Baroni A, Hernandez M, Grant M, Faedda G. Sleep disturbances in pediatric bipolar disorder: a comparison between bipolar I and bipolar NOS. Front Psychiatry 2012;3. DOI: 10.3389/fpsyt.2012. 00022.

20. Steinan MK, Scott J, Lagerberg TV, et al. Sleep problems in bipolar disorders: more than just insomnia. Acta Psychiatr Scand 2016:133:368-77. doi: 10.1111/acps.12523.

21. Roybal DJ, Chang KD, Chen MC, Howe ME, Gotlib IH, Singh MK. Characterization and factors associated with sleep quality in adolescents with bipolar I disorder. Child Psychiatry Hum Dev 2011;42:724-40. doi: 10.1007/s10578-011-0239-0.

22. Gershon A, Johnson SL, Thomas L, Singh MK. Double trouble: weekend sleep changes are associated with increased impulsivity among adolescents with bipolar I disorder. Bipolar Disord 2019;21:132-41. doi: 10.1111/bdi.12658. 